\title{
A Systems Model for Evaluating Transit Performance
}

\author{
Joanne M. Sulek and Mary R. Lind \\ Urban Transit Institute \\ North Carolina A\&T State University
}

\begin{abstract}
$\overline{\text { Abstract }}$
The purpose of this study was to illustrate how a systems modeling approach to transit performance measurement can be used to integrate the issues of service quality, efficiency, and effectiveness. The mathematical formulation of the systems model developed in this article was used to construct a single transit performance metric that can be used by elected officials, transit system personnel, taxpayers, and other decision-makers to compare similar transit systems. In this study, the systems model was applied to a set of small transit systems operating in the United States. Results revealed that fewer than one-fourth of these systems were efficiently using labor, fuels, materials, and capital to provide quality transit service.
\end{abstract}

\section{Introduction}

During the past decade, public transit systems in the United States have faced mounting public pressure to decrease operating costs, improve productivity, reduce subsidies, and increase ridership, while ensuring a level of service that is acceptable to their riders (Briddell and Arden 1998; Obeng and Ugboro 1996; Takyi, Obeng, and Ugboro 1993; Talley 1988). In addition, the growing 
emphasis on Total Quality Management (TQM) in public transit management has resulted in a need for greater public awareness of and involvement in transportation planning issues. One starting point for increased public awareness involves better understanding of transit operating costs (Cunningham, Young, and Lee, 1997).

In particular, an individual system's effectiveness in translating these costs into actual transit services may be of interest to the public, especially if this effectiveness can be characterized as being higher or lower than for comparable transit systems. Consequently, a variety of stakeholders in an individual public transit system-local planners, politicians, media, and transit system personnel-may find a summary metric of transit performance useful in describing to the public how the local system compares with other transit systems. Of course, elected officials and transit personnel may also use such a summary measure as part of the transit management process.

Currently, there is considerable disagreement within the literature about the best way to measure overall transit system performance, especially given the growing emphasis on service quality. Innovative approaches to assessing transit performance are clearly required. In response to this need, this article proposes a systems approach to measuring transit performance that integrates the issues of service quality, efficiency, and effectiveness. An example of a systems model for transit performance evaluation is presented. A mathematical model that operationalizes this illustrative model is formulated and applied to actual performance data for a set of peer transit systems. A single performance measure generated by the model is then used to classify peer transit systems as either relatively efficient or inefficient producers of multiple service outputs.

\section{Literature Review}

During the 1990s, a number of researchers cited the shortcomings of single performance ratios that have traditionally been used to evaluate public transit systems (Pullen 1993; Obeng, Assar, and Benjamin 1992; Fielding 1992). These single performance indicators are generally classified as either efficiency or effectiveness metrics (Pullen 1993; Chu, Fielding, and Lamar 1992; Talley 1988; Gleason and Barnum 1982; Fielding 1987; Talley and Anderson 
1981; Silcock 1981; Stokes 1979; Hatry 1980). Efficiency indicators measure the extent to which resources are used economically (Stuart 1997; Gleason and Barnum 1982), whereas effectiveness measures for public transit systems typically indicate "how well the [transit] services produced meet the objectives set for them" (Pullen 1993, p. 248). To a large extent, transit objectives have traditionally involved transit usage goals such as increasing the number of passengers per vehicle hour (Gleason and Barnum 1982; Stokes 1979; Fielding, Glauthier, and Lave 1978; Talley 1988). However, in recent years, quality of service has emerged as an important type of effectiveness indicator (Cunningham, Young, and Lee 1997; Talley 1988; Fielding 1992; Pullen 1993). While "there is no definitive set of quality service indicators" (Pullen 1993, p. 249), frequently cited quality measures include reliability of service, safety, comfort, and accessibility (Pullen 1993; Fielding 1992).

Since overall public transit system performance encompasses multiple dimensions, a number of researchers have called for the development of a group of performance metrics for comparing peer systems (Chu, Fielding, and Lamar 1992). While it may be appealing to use multiple measures for public transit performance, reliance on multiple metrics may pose difficulties. Obeng, Assar, and Benjamin (1992) illustrated that the use of multiple performance indicators may yield conflicting results and suggested that a possible remedy for this problem may lie in the development of a single metric "that best describes the overall performance of transit systems." In a similar vein, Chu, Fielding, and Lamar (1992, p. 224) argued that performance analysis for public transit systems must "progress from multiple measures and partial comparisons to more robust indicators of performance." Finally, some of the stakeholders in a local transit system-including elected officials, the media, and the taxpayers themselves-may actually prefer a single metric that summarizes the relative overall performance of a local transit system.

A single overall measure of transit performance possesses several characteristics that may be attractive to these stakeholders. The first trait is simplicity. This characteristic is desirable because the public may have a difficult time judging overall performance when confronted by a lengthy series of individual 
performance ratios, particularly if some of these ratios trend in opposite directions. Thus, an overall performance metric can help to remove ambiguity and confusion caused by overwhelming stakeholders with many small pieces of information. A second characteristic is that a relative overall measure facilitates comparisons between an individual system and peer systems. It is not difficult for most stakeholders to understand that a local system with a score of 0.45 or 45 percent (out of a maximum rating of 1.0 or $100 \%$ ) is somehow not performing as well as a neighboring system having a rating of 0.97 . A third characteristic is that if the overall metric is carefully constructed so that it represents the output of an appropriate and mathematically rigorous methodology, the methodology itself may provide additional insights on individual system performance. Such a methodology thus possesses explanatory power, which may help local decision-makers and elected officials interpret the rating results for the public.

Since a comprehensive performance metric, "like virtually all performance measures, must confront the possibility that the quality of transit output may improve" (Talvitie and Obeng 1991, p. 171), it must capture service quality variables as well as efficiency and effectiveness data. One way of integrating the issues of service quality, efficiency, and effectiveness is to apply a systems approach to transit performance measurement (Fielding 1987; Gleason and Barnum 1982; Abbas and Bell 1994). General systems theory "characterizes an organization as a unified system of interrelated parts" and a "systems approach filters reality so that interactions and interdependencies can be understood" (Fielding 1987, p. 2). An example of a systems model for transit performance evaluation is discussed in the following section. The theoretical version of this systems model is presented first; then, a mathematical formulation of the model is used to calculate a single overall performance metric for individual transit systems.

\section{A Systems Model for Transit Performance}

A systems approach to transit performance reflects the fact that "transit organizations are resource-dependent open systems" (Fielding 1987, p. 3). 
Thus, the systems approach not only depicts a relationship between resource inputs and service produced, it also indicates how well resources are used to meet passenger needs (Fielding 1987, p. 8). Therefore, if a single metric for overall system performance is to be developed from a systems model, that metric must reflect the efficiency, effectiveness, and quality of service of the transit system being evaluated. Figure 1 presents an example of a systems model that provides such a performance metric. In this illustrative model, multiple resource inputs are used to produce multiple service outputs.

\begin{tabular}{|l|l|l|}
\hline Resource Inputs & Transit Inputs \\
Labor & & $\begin{array}{l}\text { Service provided } \\
\text { Service consumed } \\
\text { Fuel/materials } \\
\text { Capital investment }\end{array}$ \\
\cline { 2 - 3 }
\end{tabular}

Figure 1. Systems model for transit services

The inputs of labor, fuel/materials, and capital investment are modeled as inputs because they are considered key resources in most public transit operations in the United States (Briddell and Arden 1998; Obeng, Assar, and Benjamin 1992; Fielding 1987; Chu, Fielding, and Lamar 1992; Nolan 1996). The outputs shown in Figure 1 are considered simultaneously because resource utilization not only leads to the provision of transit services, but also influences the extent to which services are consumed and how passengers perceive the quality of transit service delivery. For example, a bus driver provides transit service by operating a vehicle; however, he or she influences rider perceptions (and potential future service consumption) via driving skills (or lack thereof) and courtesy, helpfulness, and attention to passengers (Sulek, Lind, and Marucheck 1995). Similarly, maintenance labor can affect service availability (i.e., service provision) as well as service safety, consistency, and passenger comfort, which are issues related to service quality.

Table 1 lists the measures used to operationalize the input and output variables depicted in Figure 1. All of these measures are reported in the National Transit Database (formerly, Section 15 National Urban Mass Transportation 


\begin{tabular}{|c|c|}
\hline \multicolumn{2}{|c|}{$\begin{array}{c}\text { Table } 1 \\
\text { Model Operationalization }\end{array}$} \\
\hline Model Variable & Operationalization \\
\hline \multicolumn{2}{|l|}{ Resource Inputs } \\
\hline Labor & Total annual labor costs \\
\hline Fuel/materials & $\begin{array}{l}\text { Costs of maintenance materials, fuel, } \\
\text { and other inventory }\end{array}$ \\
\hline Capital investment & Fleet size \\
\hline \multicolumn{2}{|l|}{ Transit Outputs } \\
\hline Service provided & Annual revenue capacity miles \\
\hline Service consumed & Unlinked passenger trips \\
\hline Service quality & $\begin{array}{l}\text { Annual vehicle miles/annual number of } \\
\text { collision accidents }\end{array}$ \\
\hline
\end{tabular}

The source of this data is the Section 15 data for 1991, available from the U.S. Department of Transportation.

Statistics), compiled yearly by the U.S. Department of Transportation. The labor variable is represented by total annual labor costs. Labor costs tend to overshadow all other transit operating costs and comprise almost 75 percent of the total cost of producing public transit services, making total labor costs a critical component of a systems model for transit performance (Briddell and Arden 1998; Fielding 1987; Chu, Fielding, and Lamar 1992). The second variable, fuel/materials, is represented by the sum of annual costs for maintenance materials, fuels, and other inventory. The capital investment variable is measured by number of vehicles (or fleet size); the use of fleet size as a surrogate for capital investment in public transit operations is standard practice in the transit literature (Fielding 1987; Obeng, Assar, and Benjamin 1992; Nolan 1996).

Three measures are used in Table 1 to operationalize the model's output variables. The service-provided variable is measured by annual revenue capacity miles, which is defined as "actual revenue vehicle miles multiplied by the average passenger capacity of the active revenue vehicles in the fleet." Average passenger capacity is calculated by "averaging the sum of the seated capacity and standing capacity of all active vehicles in the fleet" (Glossary of Transit Terms 1990, p. 12). Annual revenue capacity miles is viewed in the transit lit- 
erature as an appropriate metric for service provided because it measures the service capacity produced, "expressed in nonmonetary terms" (Fielding 1987, p. 64). The second output variable, service consumed, is measured by the frequently used effectiveness metric unlinked passenger trips (see Chu, Fielding, and Lamar 1992). Fielding (1987, p. 76) notes that "unlinked passenger trips are the most reliable statistic from the Section 15 data and are preferred" for comparative studies. The service quality variable is represented by the operating safety metric vehicle miles between collision accidents (Stuart 1997; Fielding 1992). Safety is considered a key indicator of how transit service quality is defined by riders (Pullen 1993; Silcock 1981); number of collision accidents (as opposed to number of total accidents) is used in the denominator because collision accidents are reported more reliably in the Section 15 data (Fielding 1987, p. 77).

The variety of input and output variables comprising the systems model described above may appear to preclude their combination in one performance measure of transit services. However, a single measure of relative transit system performance can be constructed through the use of mathematical optimization methods so that the multiple inputs and outputs of the systems model can be considered simultaneously. The calculation of this overall performance metric is described in the following section.

\section{Mathematical Formulation of the Systems Model}

A mathematical formulation of this systems model for transit performance can be accomplished through a mathematical programming model known as Data Envelopment Analysis (DEA), originally proposed by Charnes, Cooper, and Rhodes (1981). DEA can be used to determine the relative efficiency of each member of a set of comparable transit agencies by computing for each transit system a ratio of weighted resource input values to weighted service output values. For each transit system, the DEA procedure will select the input and output weights that maximize the relative efficiency ratio for that system. Since the transit systems within a peer group use different combinations of resource inputs to provide different levels of service outputs, the weights produced by the DEA procedure will vary from system to system. However, all 
DEA-generated weights will be nonnegative and any peer system could apply the weights for a specific system to calculate its own performance ratio, which would be less than or equal to 1 in value (Sexton 1986, p.10).

The following is a formal mathematical model for the DEA procedure:

$$
\begin{gathered}
\operatorname{Max} h_{k}=\frac{\sum_{r=1}^{3} u_{r k} y_{r k}}{\sum_{i=1}^{3} v_{i k} x_{i k}} \\
\text { subject to: } \frac{\sum_{r=1}^{3} u_{r k} y_{r j}}{\sum_{i=1}^{3} v_{i k} x_{i j}} \leq 1
\end{gathered}
$$

where: $j=1, \ldots . ., n$

$$
u_{r k}, v_{i k} \geq o ; r=1,2,3 ; i=1,2,3
$$

where:

$x_{i j}=$ observed amount of input $i$ used by $j^{\text {th }}$ transit system,

$y_{r j}=$ observed amount of output $r$ generated by $j^{\text {th }}$ transit system,

$h_{k}=$ relative efficiency score for transit system $k$,

$u_{r k}=$ weight for output $r$ used by transit system $k$,

$v_{i k}=$ weight for input $i$ used by transit system $k$,

$n=$ number of transit systems compared.

The objective function for transit system $k$ is expressed in fractional form, with the numerator equal to the weighted sum of annual revenue capacity miles, unlinked passenger trips, and vehicle miles between collisions. The denominator 
is the weighted sum of annual labor costs, fuel/materials costs, and fleet size. The maximum value of this ratio $\left(h_{k}\right)$ is the performance measure for system $k$. The $n$ fractional constraints indicate each of the $n$ peer transit systems would have a performance ratio less than or equal to $l$ if system $k$ 's input/output weights were used to construct the ratio. The remaining constraints in the model indicate that the weights for system $k$ 's inputs and outputs are nonnegative.

Since there are $n$ peer transit systems to be compared, $n$ performance ratios must be computed; this requires $n$ iterations of the model shown above (one iteration per transit system). The DEA model ensures that the optimal performance ratio $\left(h_{k}\right)$ for each transit system will be a number between 0 and 1 , with higher ratios indicating higher overall performance. If transit system $k$ has a ratio less than 1 (i.e., $h_{k}<1$ ), then that system is said to be relatively inefficient in converting multiple system inputs into multiple outputs. Charnes, Cooper, and Rhodes (1981, p. 669) define a system as inefficient if "it is possible to augment any output without increasing any input and without decreasing any other output" or "decrease any input without augmenting any other input or without decreasing any outputs." Thus, inefficient systems consume too much input (relative to efficient systems) in producing their outputs.

While DEA appears to be an attractive technique for optimizing transit performance, its usefulness has remained largely unrecognized in the transportation literature. Notable exceptions include studies by Kusbiantoro (1985); Chu, Fielding, and Lamar (1992); Kerstens (1996); and Nolan (1996). Kusbiantoro's work analyzed transit systems exhibiting a wide range of average operating speeds and peak-to-base ratios. Since these systems were not truly comparable, the study violated a requirement of DEA that systems are similar. Kerstens (1996) and Nolan (1996) focused on system efficiency only and formulated a single output DEA model to measure transit performance. Chu, Fielding, and Lamar (1992) proposed two separate DEA models to investigate transit system efficiency and effectiveness. Each model contained only one service output. In the first DEA model, annual vehicle revenue hours was the output variable used to examine the issue of service efficiency. In the second DEA model, service effectiveness was investigated through the use of 
annual unlinked passenger trips as the output variable. Although Chu, Fielding, and Lamar (1992) recognized the importance of modeling both transit efficiency and effectiveness, they did not attempt to combine these constructs into a single measure of system performance, as called for in the literature (Pullen 1993; Obeng, Assar, and Benjamin 1992). In contrast, the DEA model given above encompasses both concepts while simultaneously accounting for quality variables.

\section{Model Application}

The DEA/systems model was used to analyze the overall performance of a set of 27 peer transit systems operating in the United States. Fielding's (1987) typology for bus transit was used to classify these 27 systems as peers. The variables used by Fielding to create this typology were size, peak-to-base operating ratio, and average operating speed. All 27 systems served small cities (with populations between 50,000 and 145,000) and no system required more than 25 vehicles for peak service. Furthermore, each system in the peer group had an operating peak-to-base ratio of 1.45 or less and an average operating speed between 11 and 16 miles per hour. Thus, these bus systems were comparable and the DEA model, which assumes similar systems, could be applied (Fielding 1987, p. 46).

DEA results revealed that 21 of the 27 bus systems analyzed had performance ratios less than 1 ; therefore, these 21 systems were relatively inefficient in converting input resources (labor, fuel/materials, and capital) into service outputs (see Table 2). The remaining 6 systems, which had performance ratios equal to 1 , are referred to as boundary points. A system that corresponds to a boundary point is a relatively efficient system only if the slack variables from the associated dual linear program are all 0 (or, equivalently, if the constraints from the dual program hold at equality). Table 2 shows that 6 transit systems have performance ratios equal to 1 as well as 0 -valued slacks. Thus, these 6 systems display the highest relative performance in the group of 27 transit systems.

Once the relatively efficient systems have been determined, dual model results from the DEA procedure can be used to gain additional information about the inefficient systems. The solution for the dual program for an ineffi- 


\section{Table 2}

Performance Ratios and Slack/Surplus Variables by Transit System

\begin{tabular}{|c|c|c|c|c|c|c|c|}
\hline Transit Sustem & $\begin{array}{l}\text { Performan } \\
\text { Ratios }\end{array}$ & $\begin{array}{c}\text { Vehicle } \\
\text { Miles } \\
\text { e betreen } \\
\text { Collisions }\end{array}$ & $\begin{array}{c}\text { Unlinked } \\
\text { Passenger } \\
\text { Trips }\end{array}$ & $\begin{array}{c}\text { Capacity } \\
\text { Miles }^{*}\end{array}$ & $\begin{array}{l}\text { Labor } \\
\text { Cost }\end{array}$ & $\begin{array}{l}\text { Fuel } \\
\text { Materials } \\
\text { Cosr }\end{array}$ & $\begin{array}{l}\text { Fleet } \\
\text { Cost }\end{array}$ \\
\hline \multicolumn{8}{|l|}{ Efficient Systems } \\
\hline Bloomington BPT, IL & 1.0000 & 0 & 0 & 0 & 0 & 0 & 0 \\
\hline Eau Claire, WI & 1.0000 & 0 & 0 & 0 & 0 & 0 & 0 \\
\hline La Crosse, WI & 1.0000 & 0 & 0 & 0 & 0 & 0 & 0 \\
\hline LA Culver, CA & 1.0000 & 0 & 0 & 0 & 0 & 0 & 0 \\
\hline Pensacola, FL & 1.0000 & 0 & 0 & 0 & 0 & 0 & 0 \\
\hline Tuscaloosa, AL & 1.0000 & 0 & 0 & 0 & 0 & 0 & 0 \\
\hline \multicolumn{8}{|l|}{ Inefficient Systems } \\
\hline Abeline AT, TX & 0.6430 & 22.19 & 0 & 0 & 0 & 0 & 0 \\
\hline Athena ATS, GA & 0.9066 & 290.2 & 0 & 0 & 0 & 0 & 0 \\
\hline Beloit, WI & 0.7729 & 80.82 & 0 & 4.74 & 0 & 0 & 0 \\
\hline Burlington, VT & 0.5300 & 1.49 & 0 & 0 & 0 & $\$ 53.71$ & 4.10 \\
\hline Cumberland, MD & 0.9184 & 318.25 & 0 & 0 & 0 & 0 & 0 \\
\hline \multicolumn{8}{|l|}{ Fayetteville- } \\
\hline East, NC & 0.7484 & 0 & 0 & 0 & $\$ 7.06$ & $\$ 263.54$ & 0 \\
\hline \multicolumn{8}{|l|}{ Galveston- } \\
\hline Island, TX & 0.8229 & 114.74 & 0 & 0 & 0 & 0 & 0 \\
\hline Glenn Falls, NY & 0.07895 & 0 & 0 & 2553.33 & 0 & 5.71 & 0 \\
\hline Greenley, CO & 0.8328 & 0 & 139.71 & 3037.11 & 0 & $\$ 211.68$ & 0 \\
\hline Hagerstown, MD & 0.7225 & 201.45 & 20.51 & 0 & 0 & 0 & 0 \\
\hline Jackson, TN & 0.8664 & 252.34 & 312.75 & 0 & 0 & 0 & 0 \\
\hline LaFayette-COLT, LA & 0.8422 & 0 & 0 & 0 & 0 & $\$ 71.81$ & 0 \\
\hline LA Norwalk, CA & 0.9272 & 25.84 & 1118.41 & 0 & 0 & 0 & 0.72 \\
\hline Lynchburg, VA & 0.9581 & 76.82 & 0 & 0 & 0 & $\$ 149.13$ & 2.69 \\
\hline Monroe-MTS, LA & 0.9906 & 0 & 0 & 0 & 0 & $\$ 114.15$ & 2.64 \\
\hline Portland Metro, OR & 0.7754 & 2.38 & 0 & 0 & $\$ 2.03$ & 0 & 0 \\
\hline Rockford-Lanes, IL & 0.9525 & 0 & 27.43 & 0 & $\$ 39.45$ & $\$ 12.71$ & 0 \\
\hline St. Cloud Metro, MN & 0.8494 & 105.17 & 0 & 0 & 0 & 0 & 0 \\
\hline St. Joseph, MO & 0.7936 & 125.01 & 281.08 & 0 & 0 & 0 & 0 \\
\hline Wilmington-WT, NC & 0.9590 & 0 & 0 & 0 & $\$ 15.52$ & 0 & 0 \\
\hline Williamsport, PA & 0.8873 & 95.87 & 0 & 0 & $\$ 3.57$ & 0 & 0 \\
\hline
\end{tabular}

'In thousands. 


\begin{tabular}{|c|c|c|c|c|c|c|c|}
\hline & Actu & $\begin{array}{l}\text { Values } \\
\text { Hage }\end{array}$ & $\begin{array}{l}\text { Table } \\
\text { or Input/ } \\
\text { town's Re }\end{array}$ & $\begin{array}{l}\text { itput } \\
\text { renc }\end{array}$ & $\begin{array}{l}\text { Variable } \\
\text { e Set }\end{array}$ & for & \\
\hline System i & $\lambda_{i}$ & $\begin{array}{l}\text { Labor } \\
\text { Cosi }{ }^{a}\end{array}$ & $\begin{array}{c}\text { Fuel/Materials } \\
\text { Cosp }^{p}\end{array}$ & $\begin{array}{l}\text { Fleet } \\
\text { Sizea }\end{array}$ & $\begin{array}{c}\text { Revenue } \\
\text { Capacity } \\
\text { Miles }\end{array}$ & $\begin{array}{l}\text { Unlinked } \\
\text { Passenger } \\
\text { Tripsa }\end{array}$ & $\begin{array}{c}\text { Vehicle } \\
\text { Miles } \\
\text { between } \\
\text { Collisionsa }\end{array}$ \\
\hline Bloomington & 0.34027 & $\$ 446.00$ & $\$ 29,256.00$ & 14 & $39,853.60$ & 858.20 & 223.60 \\
\hline Eau Claire & 0.04735 & $\$ 466.00$ & $\$ 13,798.00$ & 12 & $24,553.80$ & 846.30 & 495.90 \\
\hline Tuscaloosa & 0.43597 & $\$ 536.00$ & $\$ 8,011.00$ & 6 & $13,688.90$ & 381.50 & 290.00 \\
\hline
\end{tabular}

${ }^{a}$ In thousands.

cient transit system furnishes a set of efficient systems known as an efficient reference set which can be used to identify inefficiencies in that system's use of inputs. For instance, DEA results showed that the Hagerstown system had a performance ratio of 0.7225 , which is clearly inefficient (see Table 2). The transit systems for Tuscaloosa, Eau Claire, and Bloomington BPT formed the efficient reference set for this inefficient system because the dual variables (or lambda values) associated with these three systems are non- 0 in the dual version of the DEA program for Hagerstown. The actual resource input values and output levels for Tuscaloosa, Eau Claire, and Bloomington BPT are shown in Table 3; also listed are the lambda values $\left(\lambda_{i}\right)$ for these three systems. Table 4 shows the actual and projected values for the input and output variables for the Hagerstown system. Each projected input (output) value is a linear combination of the actual values on that variable used by Tuscaloosa, Eau Claire, and

\begin{tabular}{|c|c|c|c|c|c|c|}
\hline \multicolumn{7}{|c|}{$\begin{array}{c}\text { Table } 4 \\
\text { Actual and Projected Input/Output Variables for } \\
\text { Hagertown's System }\end{array}$} \\
\hline & Labor $\operatorname{Cos}^{a}$ & Material Cosi ${ }^{a}$ & Fleet Size & $\begin{array}{c}\text { Revenue } \\
\text { Capacity/Milesa }\end{array}$ & $\begin{array}{c}\text { Unlinked } \\
\text { Passenger } \\
\text { Tripsa }\end{array}$ & $\begin{array}{c}\text { Vehicle Miles } \\
\text { between } \\
\text { Collisions } \\
\end{array}$ \\
\hline Actual values & $\$ 564.00$ & $\$ 19,516.37$ & 11 & $20,691.50$ & 477.90 & 24.55 \\
\hline Projected values & $\$ 407.50$ & $\$ 14,101,00$ & 8 & $20,691.50$ & 498.41 & 226.00 \\
\hline
\end{tabular}

${ }^{a}$ In thousands. 
Bloomington BPT and the corresponding lambda values. For example, for the Hagerstown system:

Projected labor cost $($ in thousands $)=\$ 407.5=[0.34027(446.0)+.04735(466.0)+0.43597(536.0)](1)$

Similar computations yield the other projected values given in Table 4 .

Table 4 indicates that, within the context of this particular model, the Hagerstown system is a relatively inefficient system because it consumes an excess of resources (labor costs, fuel/materials cost, fleet size) while underproducing two outputs-unlinked passenger trips and vehicle miles between collisions. Thus, the DEA results can be used within a systems approach to transit performance to help explain why a particular system is a relatively inefficient one.

In interpreting DEA results, it is advisable to examine how relatively efficient systems earned their maximum ratios. Within a group of peer transit systems it is possible to have "specialist" systems that concentrate exclusively on improving a single output variable. For instance, a transit system may emphasize service provided (an efficiency metric) to a far greater degree than the other systems in its peer group but exhibit mediocre service consumption (effectiveness) and quality metrics, compared to peer systems (Chu, Fielding, and Lamar 1992). Such "variations in emphasis between different authorities' objectives, as expressed in the output measures, are perfectly legitimate" in DEA modeling (Smith and Mayston 1987, p. 188). However, DEA will assign a ratio of 1 to this "specialist" system because its performance in service provision eclipses that of its peer systems, given the level of input resources used. Giokas (1991) and Smith and Mayston (1987) note that the efficient reference sets of inefficient systems differentiate "specialist" systems from "robustly efficient" systems (i.e., those systems whose maximum ratings do not result solely from superior performance on a unique output measure). A system that appears to be relatively efficient but does not belong to the efficient reference set of any inefficient system is a "specialist." Since the La Crosse system is not contained in the efficient reference set of any inefficient system in this study, it is a specialist system. Examination of actual data values reveals that, given 
its use of resource inputs, the La Crosse system exhibits outstanding performance on only one output variable-annual revenue capacity miles.

\section{Discussion}

This study proposed a systems-based model of transit performance that links multiple inputs to the core service outputs of quality, efficiency, and effectiveness. A single metric of relative overall performance is developed using a DEA formulation of the systems model. Not only does the DEA methodology furnish a performance measure that may prove useful to elected officials, transit personnel, media, taxpayers, and other stakeholders in a particular transit system, it also helps to explain, via analysis of the dual problem, why a particular system with a low rating is relatively inefficient. Dual problem analysis also helps to identify specialist systems, which attain the maximum rating due to outstanding performance on one aspect of service delivery.

The systems approach presented in this research is unique in that it models transit output as a multidimensional vector consisting of service quality, service provision, and service consumption. Previous systems models of transit performance (e.g., Fielding 1987; Chu, Fielding, and Lamar 1992) used a sequential approach, depicting service provision as an input to service consumption. For instance, in Chu, Fielding, and Lamar's (1992) study, two DEA models are used sequentially to evaluate performance. In the first DEA model (the efficiency model), service provision is the sole output variable while in the second DEA model (the effectiveness DEA), service provision is one of the inputs linked to service consumption, the single output variable.

The problem with this sequential modeling of transit service is that in actual transit operations it is possible to improve service quality and consumption without ever altering the level of the service provision variable. For example, a bus without air-conditioning during a heat wave may discourage ridership without ever affecting the number of vehicle operating hours compiled (service provided). Fixing the broken air-conditioning system will improve riders' perceptions of transit quality and encourage them to use the service again (thereby increasing consumption). In this example, labor and repair supplies and parts directly affect transit consumption and quality without affecting vehi- 
cle operating hours (the output of the "efficiency DEA" in sequential DEA modeling). In general, a single DEA model that links input resources to the multiple outputs of service quality, service provision, and service consumption better exploits the power of DEA methodology to identify inefficiencies than a series of single output DEA models.

While DEA provided a useful mathematical realization of the systems model of transit performance presented in this article, there are several considerations regarding its application that should be taken into account. First, DEA is sensitive to data inaccuracies, particularly if these involve efficient systems. Use of unreliable or misspecified data for these systems can affect the performance ratios of the remaining peer systems. (All data used in the DEA model are found in the National Transit Database, which Chu, Fielding, and Lamar [1992, p. 223] label "a superb national data set" in which "variables are appropriately defined and validated.") Second, omission of an important output variable from the model will distort the DEA results (Smith and Mayston 1987, p. 188). For instance, if service provided is modeled as the sole output of transit performance, systems that excel in service quality and effectiveness could unfairly be characterized as relatively low performers. Third, inclusion of too many variables will also distort DEA results; therefore, sample size must be adequate given the total number of variables used. Golany and Roll (1989) and Fitzsimmons and Fitzsimmons (1994, pp. 321-322) suggest that the number of systems analyzed should exceed twice the sum of all input and output variables. (In this study, the number of transit systems [27] was greater than twice the sum [6] of model variables.)

The specific DEA model discussed in this article serves as an example of the systems modeling approach for transportation performance evaluation. Clearly, this particular model is not without limitations. While this specific model utilized labor costs, fuel/materials costs, and fleet size as inputs, other input variables such as subsidies and expenditures on facilities, signage, shelters, and advertising could be added to future research models. Similarly, other measures of service quality could be included as output variables. These metrics could be drawn from operating data or be based on customer perceptions 
of service quality that are captured through onboard surveys, phone interviews, focus groups, etc. These service variables could encompass a variety of transit service issues including reliability, driver courtesy, security, and service accessibility. Greater refinement of the topology for peer transit systems constitutes another area for future research. While this study utilized Fieldings's (1987) taxonomy, additional classification variables may serve to further differentiate transit systems. Such variables include geography, demographics, climate, congestion, and availability of parking.

In summary, the systems approach to transit performance can provide a potentially useful tool for simultaneously modeling service inputs and the key service outputs of service quality, transit efficiency, and effectiveness. Through the use of DEA modeling, multiple criteria can be summarized with a single overall measure of transit system performance. This measure may be of value to a variety of stakeholders in a local transit system.

\section{Acknowledgments}

The authors wish to acknowledge the North Carolina A\&T Urban Transit Institute and the U.S. Department of Transportation for funding this research. The authors also thank Dr. Kofi Obeng for his suggestions and encouragement during the research project.

\section{References}

Abbas, K. A., and M. G. H. Bell. 1994. System dynamics applicability to transportation modeling. Transportation Research A 28A (5): 373-400.

Briddell, E. T., and M. B. Arden. 1998. How to build a better transit system. Mass Transit 24 (2): 21-27.

Charnes, A., W. W. Cooper, and E. Rhodes. 1981. Evaluating program and managerial efficiency: An application of data envelopment analysis to program follow through. Management Science 27 (6): 668-697.

Chu, X., G. J. Fielding, and B. W. Lamar. 1992. Measuring transit performance using data envelopment analysis. Transportation Research 26A (3): 223-230.

Cunningham, L. F., C. E. Young, and M. Lee. 1997. Developing customer-based measures of overall transportation service quality in Colorado: Quantitative and qualitative approaches. Journal of Public Transportation 1 (4): 1-21. 
Fielding, G. J. 1987. Managing public transit strategically. San Francisco: JosseyBass, Inc.

Fielding, G. J. 1992. Transit performance evaluation in the U.S.A. Transportation Research A 26A (6): 483-491.

Fielding, G. J., R. E. Glauthier, and C. A. Lave. 1978. Performance indicators for transit management. Transportation 7 (4): 365-379.

Fitzsimmons, J., and M. Fitzsimmons. 1994. Service management for competitive advantage. New York: McGraw-Hill.

Giokas, D. 1991. Branch bank operating efficiency: A comparative application of DEA and the loglinear model. Omega 19 (6): 549-557.

Gleason, J. M., and D. T. Barnum. 1982. Toward valid measures of public sector productivity: Performance measures in urban transit. Management Science 28 (4): 379-386.

Glossary of Transit Terms. 1990. U.S. Department of Transportation, Federal Transit Administration.

Golany, B., and Y. Roll. 1989. An application procedure for DEA. Omega 17 (3): 237-250.

Hatry, H. P. 1980. Performance measurement principles and techniques: An overview for local government. Public Productivity Review 4: 312-319.

Kerstens, K. 1996. Technical efficiency measurement and explanation of French urban transit companies. Transportation Research A, 30 (6): 431-452.

Kusbiantoro, X. 1985. A study of urban mass transit performance: Concept, measurement, and explanation. Unpublished Ph.D. dissertation. University of Pennsylvania, Philadelphia, Pennsylvania: The School of Public and Urban Policy.

Nolan, J. F. 1996. Determinants of productive efficiency in urban transit. Logistics and Transportation Review 32 (3): 319-343.

Obeng, K., N. Assar, and J. Benjamin. 1992. Total factor productivity in transit systems: 1983-1988. Transportation Research A 26A (6): 447-455.

Obeng, K., and I. Ugboro. 1996. Applications of TQM in public transit firms. Transportation Quarterly 50 (3), Summer: 79-94.

Pullen, W. T. 1993. Definition and measurement of quality service for local public transport management. Transport Reviews 13 (3): 247-264. 
Sexton, T. 1986. The methodology of data envelopment analysis. In New Directions for Program Evaluation. R. H. Silkman., ed., San Francisco: Jossey-Bass, 31-46.

Silcock, D. T. 1981. Measures of operational performance for urban bus services. Traffic Engineering and Control 22 (12): 645-648.

Smith, P., and D. Mayston. 1987. Measuring efficiency in the public sector. Omega 15 (3): 181-189.

Stokes, B. R. 1979. The need for and use of performance indicators in urban transit. Transit Journal. Winter: 3-10.

Stuart, D. G. 1997. Goal-setting and performance measurement in transportation planning and programming. Journal of Public Transportation 1 (2): 49-71.

Sulek, J. M., M. R Lind, and A. S. Marucheck. 1995. Improving service quality through customer input. Proceedings of the 1995 Meeting of the Decision Sciences Institute. Boston, MA: November 20-22: 1590-1592.

Takyi, I. K., K. Obeng, and I. Ugboro. 1993. Total quality management for public transit systems. Transportation Quarterly 47 (2): 167-183.

Talley, W. K. 1988. An economic theory of the public transit firm. Transportation Research 22B (1): 45-54.

Talley, W. K., and P. P. Anderson. 1981. Effectiveness and efficiency in transit performance: A theoretical perspective. Transportation Research A 15: 431-436.

Talvitie, A. P., and K. Obeng. 1991. Productivity and performance. Transportation Planning and Technology 15: 169-176.

\section{About the Authors}

JoANNE M. SulEK (sulekj@ncat.edu) received a bachelor's and a master's degree in mathematics from Wake Forest University. She received a doctorate in operations management from the University of North Carolina at Chapel Hill in 1989. She is currently an associate professor of operations management at the School of Business and Economics at North Carolina A\&T State University. Her research interests include technology management, service quality, quality control, and white-collar productivity. Her research has appeared in numerous publications. 
MARY R. LIND (lindm@ncat.edu) received a doctorate degree in business administration from the University of North Carolina at Chapel Hill in 1988. Prior to graduate school, she worked for 10 years as a systems analyst in the management information systems field. She is currently professor of management information systems in the School of Business and Economics at North Carolina A\&T State University. Her research interests are in the areas of innovation, computer-mediated communication channels, and the impact of technology on firm performance and service quality. Dr. Lind's work has been published in numerous research publications. 